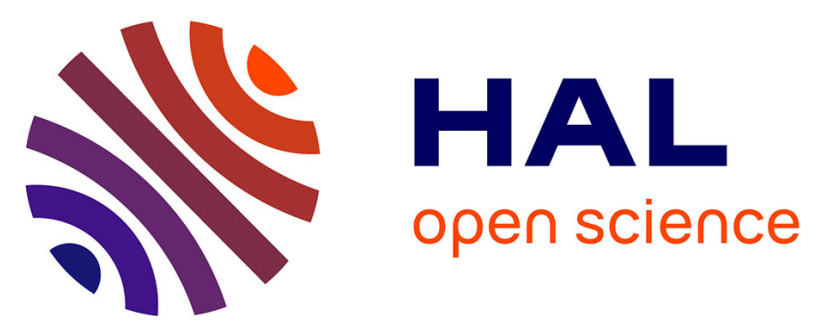

\title{
The nitric oxide donor, isosorbide dinitrate, induces a cephalic cutaneous hypersensitivity, associated with sensitization of the medullary dorsal horn Running Title: nitric oxide donors induced central sensitization
}

\author{
José Maria Ramos Flores, Laurent Devoize, Amélie Descheemaeker,
} Jean-Louis Molat, Philippe Luccarini, Radhouane Dallel

\section{To cite this version:}

José Maria Ramos Flores, Laurent Devoize, Amélie Descheemaeker, Jean-Louis Molat, Philippe Luccarini, et al.. The nitric oxide donor, isosorbide dinitrate, induces a cephalic cutaneous hypersensitivity, associated with sensitization of the medullary dorsal horn Running Title: nitric oxide donors induced central sensitization: Nitric oxide donors induced central sensitization. Neuroscience, 2017, 10.1016/j.neuroscience.2016.12.028 . inserm-01458345

\section{HAL Id: inserm-01458345 https://www.hal.inserm.fr/inserm-01458345}

Submitted on 6 Feb 2017

HAL is a multi-disciplinary open access archive for the deposit and dissemination of scientific research documents, whether they are published or not. The documents may come from teaching and research institutions in France or abroad, or from public or private research centers.
L'archive ouverte pluridisciplinaire HAL, est destinée au dépôt et à la diffusion de documents scientifiques de niveau recherche, publiés ou non, émanant des établissements d'enseignement et de recherche français ou étrangers, des laboratoires publics ou privés. 
The nitric oxide donor, isosorbide dinitrate, induces a cephalic cutaneous

hypersensitivity, associated with sensitization of the medullary dorsal horn

José María Flores Ramos ${ }^{1}$, Laurent Devoize ${ }^{1,2}$, Amélie Descheemaeker ${ }^{1}$, Jean-Louis Molat ${ }^{1}$, Philippe Luccarini ${ }^{1}$, Radhouane Dallel ${ }^{1,2}$

${ }^{1}$ Clermont Université, Université d'Auvergne, Neuro-Dol, BP 10448, F-63000, ClermontFerrand \& Inserm U1107, F-63100 Clermont-Ferrand, France; ${ }^{2} \mathrm{CHU}$ Clermont-Ferrand, Service d'Odontologie, F-63100 Clermont-Ferrand, France.

Running Title: nitric oxide donors induced central sensitization

Manuscript information: 5 figures, Words in the abstract (224), introduction (677), and discussion (1955).

\section{Correspondence to:}

Radhouane Dallel: radhouane.dallel@udamail.fr

INSERM/UdA U1107, Neuro-Dol: Douleur Trigéminale et Migraine

Faculté de Chirurgie Dentaire, 2 rue de Braga, 63100 Clermont-Ferrand, France

Tel: (33) 4731773 13, Fax: (33) 473177306 


\section{Abbreviations}

BSA, bovine serum albumin

CGRP, Calcitonin gene related peptide

ERK, Extracellular signal-regulated kinases

ISDN, Isosorbide Dinitrate

$\mathrm{MDH}$, medullary dorsal horn

NHS, normal horse serum

NTG, nitroglycerin

RM ANOVA, repeated measures analysis of variance

TBS, Tris-buffered saline

TX, Triton X

WDR, wide dynamic range 


\section{Abstract}

Nitric oxide donors are known to produce headache in healthy as well as migraine subjects, and to induce extracephalic cutaneous hypersensitivity in rodents. However, little is known on the effect of nitric oxide donors on cephalic cutaneous sensitivity. Combining behavioral, immunohistochemical, and in vivo electrophysiological approaches, this study investigated the effect of systemic administration of the nitric oxide donor, isosorbide dinitrate (ISDN), on cephalic and extracephalic cutaneous sensitivity and on neuronal activation within the medullary dorsal horn (MDH) in the rat. Systemic administration of ISDN increased selectively the first phase and interphase of the facial formalin test, but had no effect on the hindpaw formalin one. Monitoring neuronal activity within the MDH with phospho-ERK1/2 immunoreactivity revealed that ISDN alone did not activate MDH neurons, but significantly increased the number of formalin-evoked phospho-ERK1/2-immunoreactive cells in the ipsilateral, but not contralateral, MDH. Using in vivo electrophysiological unit recordings, we show that ISDN administration never affected the spontaneous activity of trigeminal wide dynamic range neurons, but, facilitated C-fiber-evoked responses in half the neurons tested. This research demonstrates that a nitric oxide donor, isosorbide dinitrate, induces selectively cephalic hyperalgesia that arises as a consequence of central sensitization in pain pathways that subserve meningeal nociception. This model better mimics the clinical condition and offers another possibility of studying the role of nitric oxide donor in the physiopathology of headache.

Keywords: Headache, pain, migraine, hyperalgesia, central sensitization, trigeminal 


\section{INTRODUCTION}

Migraine is a common disorder affecting about $15 \%$ of the population (Stovner and Andree, 2010). Cutaneous hypersensitivity is a key feature of migraine (Bigal et al., 2008). It is a consequence of central sensitization in pathways that subserve meningeal pain (Bernstein and Burstein, 2012). Cutaneous hypersensitivity may occur within only the referred area of headache (that is the periorbital region) or spread throughout the face and scalp (Ashkenazi et al., 2007; Burstein et al., 2000; Cooke et al., 2007; Guy et al., 2010; Kitaj and Klink, 2005; Yoon et al., 2009) as well as the body and limbs (Burstein et al., 2000; Guy et al., 2010). About two-thirds of migraine patients exhibit cutaneous hypersensitivity over the course of their migraine attacks (Bigal et al., 2008). The prevalence and severity of cutaneous hypersensitivity are higher in chronic than episodic migraine patients (Bigal et al., 2008). Cutraneous allodynia has thus been suggested as a risk factor for disease progression (Bigal et al., 2008) or no remission (Manack et al., 2011). Therefore, assessing cutaneous sensitivity in animals in response to known migraine triggers has been proposed as a useful approach to modeling migraine (Boyer et al., 2014; Oshinsky and Gomonchareonsiri, 2007; Pradhan et al., 2014). For instance, in rats, dural stimulation with an inflammatory soup induces both cephalic and extracephalic allodynias (Boyer et al., 2014; Edelmayer et al., 2009; Oshinsky and Gomonchareonsiri, 2007), that is associated with trigeminospinal central sensitization (Boyer et al., 2014) and impaired descending inhibitory (Boyer et al., 2014) and/or facilitatory (Edelmayer et al., 2009) pain controls.

Systemic administration of nitroglycerin (NTG) is an extensively used model of migraine in both human and animals (Ashina et al., 2013). In healthy subjects, systemic NTG triggers a headache. In migraineurs, it induces, in addition, a delayed headache with migraine features (Ashina et al., 2013). Such NTG-induced migraine-like headache is associated with thermal 
cephalic allodynia (de Tommaso et al., 2004). In rodents, systemic NTG produces extracephalic both thermal and mechanical allodynia (Bates et al., 2010; Brennan et al., 2013; Ferrari et al., 2016; Pradhan et al., 2014; Tassorelli et al., 2003), as well as hyperalgesia at the hindpaw formalin test (Greco et al., 2015; Tassorelli et al., 2003). However, this results are not in agreement with clinical studies reporting that migraine headache does not typically produce cutaneous hypersensitivity below the C8 dermatome (Ashkenazi et al., 2007). Surprisingly, though, only few studies have examined the effect of systemic administration of nitric oxide donors on cephalic cutaneous sensitivity. Moreover, they provided conflicting results. One study performed on only 3 restrained rats reported that systemic administration of NTG decreases the periorbital von Frey thresholds (Oshinsky and Gomonchareonsiri, 2007). Two other studies in mice found either a decrease (Farkas et al., 2016) or no change (Kaufmann et al., 2005) in the periorbital von Frey thresholds after systemic NTG. Similarly, either an increase in rats (Greco et al., 2015) or no change in mice (Grigoraay et al., 2013) in the duration of the face rubbing behavior was found after formalin injection into the upper lip in rats that had been pre-treated with NTG. Finally, two studies found that NTG administration raises the duration of the face rubbing behavior induced by the subcutaneous injection of Calcitonin gene related peptide (CGRP) into the upper lip (Capuano et al., 2014; Yao and Sessle, 2008). Therefore, combining behavioral, immunohistochemical, and in vivo electrophysiological approaches, this study investigated the effect of systemic administration of the nitric oxide donor, isosorbide dinitrate (ISDN), on cephalic and extracephalic cutaneous sensitivities and on the medullary dorsal horn (MDH) neuronal activation. ISDN was selected because: i) it reliably produces headache in migraineurs but less often in healthy subjects (Bellantonio et al., 1997; Castelleno et al., 1998), ii) it is less hypertensive than NTG (Manabe et al., 2001), iii) it has an injectable form, so the same solution can be injected in humans as well as animals, allowing comparison between preclinical and clinical results, and iv) it does not need to be 
dissolved in alcohol and propylene glycol, thereby reducing non-specific effects (Olesen and Jansen-Olesen, 2012). 


\section{EXPERIMENTAL PROCEDURES}

\section{Animals}

Animal experiments were performed according to the ethical guidelines of the International Association for the Study of Pain (Zimmermann, 1983), the Directive 2010/63/UE of the European Parliament and the Council on the protection of animals used for scientific purpose. Protocols for animal care and use applied in this work were approved by the appropriate local committee at the University of Clermont-Ferrand-Auvergne (no. CE 28-12).

Adult male Sprague-Dawley rats (250-275 g; Charles River, L’Arbresle, France) were raised at $23 \pm 1{ }^{\circ} \mathrm{C}$ in plastic cages (3-4 rats per cage; held in Iffa- Credo units) with soft bedding and water and food ad libitum in a 12-h/12-h dark/light cycle for at least one week before experiment. All efforts were made to minimize the number of animals used. Numbers of animals were selected according to previous experience (Boyer et al., 2014; Lapirot et al., 2011; Miraoucourt et al., 2009; Raboisson and Dallel, 2004), that is a balance between usual sample sizes in the field and the need to reduce the use of animals in pain experiments. Experiments were performed on 74 animals (6-8 rats/group). All experimenters were blind to treatment conditions. Rats were randomized into treatment groups before any assessment.

\section{Behavioral testing}

\section{Habituation}

Animal were tested in light conditions, between 11:00 and 19:00 h, in a quiet room, at 23$24^{\circ} \mathrm{C}$. Test boxes $(30 \times 30 \times 30 \mathrm{~cm})$ had 3 mirrored sides. Animals were habituated for 2 days in the test environment. During each day, animals were first placed in this test box for 30-min to minimize stress. They were then gently restrained and the experimenter simulated an 
injection into the vibrissae area or the hindpaw, using a similar syringe as that in the real test. During behavioral tests, rats had access to neither water nor food. Each rat was used only once. At the end of the experiment, the rat was killed by intraperitoneal (i.p.) injection of a lethal dose of urethane $(>1.5 \mathrm{~g} / \mathrm{kg})$ and death was confirmed by permanent cessation of cardio-respiratory functions.

\section{Face formalin test}

Animals were randomly included into 4 groups (6-8 rats/group). Rats were injected with formalin (50 $\mu 1,1 \%$ into the right vibrissa pad; Raboisson and Dallel, 2004) and then placed into the test box for a 45-min period. This observation period was divided into 15 3-min blocks. We computed a nociceptive score for each block: the time (in seconds) the animal spent rubbing the vibrissa pad with only the forepaw. The rubbing behavior was recorded using a videocamera. Formalin was injected either $2 \mathrm{~h}$ after i.p. administration of saline or 1, 2 or $4 \mathrm{~h}$ after i.p. administration of isosorbide dinitrate (ISDN, $10 \mathrm{mg} / \mathrm{kg}$, Sanofi-aventis, France).

\section{Hindpaw formalin test}

Rats were randomly included into 2 groups ( 8 rats/group) and received formalin (50 $\mu 1,1 \%)$ into the right plantar hindpaw (Abbott et al., 1995). After injection, animals were placed into the test box for a 45-min period. This observation period was divided into 15 3-min blocks. We computed a nociceptive score for each block: the time (in seconds), the animal spent licking the right hindpaw. The licking behavior was recorded using a videocamera. Formalin was injected $2 \mathrm{~h}$ after intraperitoneal administration of either saline or ISDN $(10 \mathrm{mg} / \mathrm{kg})$. 


\section{Immunocytochemistry}

MDH activation was studied using phospho-extracellular signal-regulated kinase (ERK) expression. Rats were randomly included into 2 groups (8 rats/group) and received formalin $(50 \mu 1,1 \%)$ into the right vibrissa pad $2 \mathrm{~h}$ after i.p. administration of either saline or ISDN (10 $\mathrm{mg} / \mathrm{kg})$. Five min after formalin injection rats were anesthetized with urethane $(1.5 \mathrm{~g} / \mathrm{kg}$, i.p. $)$ and perfused transcardially with heparinized saline (25 IU heparin/mL, at $37^{\circ} \mathrm{C}$ ) and then phosphate-buffered solution $\left(0.1 \mathrm{M}, \mathrm{pH} 7.6\right.$ at $\left.10^{\circ} \mathrm{C}\right)$ containing $4 \%$ paraformaldehyde $+0.03 \%$ picric acid for $15 \mathrm{~min}$. The brain was then removed and proceeded as previously described (Alvarez et al., 2009; Miraucourt et al., 2009; Peirs et al., 2016). To characterize the population of pERK1/2 immunopositive cells, double immunofluorescence labeling for pERK1/2 and the neuronal marker NeuN was performed in one set of MDH slices.

To analyze bright-field images of representative labeling, we used a charge-coupled device color video camera (Sony DXC-950P) connected to a Nikon Optiphot-2 microscope. Images were then transformed into Adobe PhotoShop (CS2) files to adjust brightness and contrast before setting the image scale.

In each rat, we computed the number of phospho-ERK ${ }^{+}$neurons within the different MDH laminae at 7 different rostrocaudal planes, between levels 0 and 2400 caudal to the obex. Given the $400-\mu \mathrm{m}$ inter-plane interval between planes, cells could not be counted twice. Our own myelo-architectural together with the Paxinos and Watson atlas (2007) were used to delineate MDH. Data are the number of labeled cells/section that were analyzed in each rat.

\section{Electrophysiology}

\section{Animal preparation}

Animal surgery for in vivo electrophysiological recordings within the MDH were performed under $2 \%$ halothane in a $\mathrm{NO}_{2} / \mathrm{O}_{2}$ mixture as previously described (Boyer et al., 2014; Lapirot 
et al., 2011). For the remainder of the experiment, anesthesia was reduced to $0.6-0.7 \%$ halothane.

\section{Unitary extracellular recordings}

Glass microelectrodes (7-10 Mohm) filled with $5 \% \mathrm{NaCl}$ containing pontamine sky blue were used to record single-unit activities within the right MDH. The brainstem was explored $0.4-2.1 \mathrm{~mm}$ laterally to the midline and between the frontal planes AP - 0.8 and AP - $2.4 \mathrm{~mm}$ from the interaural line (Paxinos and Watson, 2007). The electrophysiological setup was essentially as described previously (Boyer et al., 2014; Lapirot et al., 2011). Mechanical noxious (pinch with forceps) and innocuous (paint brush) stimulations of cutaneous receptive fields were performed to characterize wide-dynamic range (WDR) neurons (Boyer et al., 2014; Lapirot et al., 2011). Every neuron responding to stimuli from innocuous to noxious intensity with progressively increasing firing rates was classified as WDR neuron. Electrical stimuli (2ms duration) were delivered to the cutaneous receptive field through two subcutaneous stainless steel needle electrodes and the thresholds for A- and C-fiber-evoked responses determined. Aand C-fiber-evoked responses within poststimulus histograms were dissociated based on their latencies: responses with a latency $>30 \mathrm{~ms}$ were considered as C-fiber-evoked (Boyer et al., 2014; Lapirot et al., 2011).

Only C-fiber-evoked responses were analyzed. One neuron was recorded per animal, and only neurons with stable spike amplitude or waveform over the whole experimental procedure were included in the present report.

\section{C-fiber-evoked responses to peripheral electrical stimuli}

Sequences of 30 electrical stimuli (at $0.66 \mathrm{~Hz}$ ) were applied to the receptive field at 1.5 time the threshold for C-fiber activation at 15-min intervals (Boyer et al., 2014; Lapirot et al., 2011). This interval was the shortest that allowed full recovery of the responses to baseline levels. 
ISDN was slowly injected $(10 \mu \mathrm{g} / \mathrm{min})$ into the jugular vein over $120 \mathrm{~min}$ after two stable (variation in $\mathrm{C}$-fiber response $<10 \%$ ) control sequences. C-fiber-evoked responses were normalized to baseline - the two control sequences before ISDN administration - and were considered as potentiated when they were $\geq 120 \%$ of baseline. The criterion that was selected for potentiation of the neuronal responses corresponds to more than 4 times the mean standard deviation of the two successive stable - that is, a variation in C-fiber response $<10 \%$ - control sequences.

\section{Statistical analysis}

Data on formalin induced rubbing behavior were analyzed using one-way analysis of variance (ANOVA) followed by Fisher LSD post-hoc test (normally distributed data) or Kruskal-Wallis ANOVA on ranks followed by Dunn's post-hoc test (non-normally distributed data). Data on p-ERK-immunorecative cells were analyzed using either paired Student $\mathrm{t}$ test, one-way repeated measures (RM) ANOVA followed by Fisher LSD post-hoc test (normally distributed data) or two-way ANOVA followed by Duncan's post-hoc test, with treatment and lamina or level as factors (non-normally distributed data). The effect of ISDN administration on C-fiber-evoked responses was assessed by comparing values at different delays $(15,30,45$, $60,75,90,105$ and $120 \mathrm{~min}$ ) after administration with those before or baseline using one-way RM ANOVA followed by Dunnett's post-hoc test. The level of significance was set at $\mathrm{P}<0.05$. Normally distributed data are expressed as mean \pm standard error of the mean (SEM) while non-normally distributed data are presented in the figures as median, first and third quartiles (boxes) and minimum-maximum (whiskers).

\section{Histological analysis}


At the end of experiments, a pontamine sky blue solution was injected to mark the position of the recording site. The rat was then killed by intravenous lethal dose of chloral hydrate (10\%), the brain was removed and prepared for histological examination (see Chebbi et al., 2014). fixed in a $10 \%$ formalin solution for seven days. The tissue was frozen, cut into serial $100-\mu \mathrm{m}-$ thick sections, and stained with neutral red. The position of the recording sites were determined according to the Paxinos and Watson atlas (2007).

\section{RESULTS}

\section{Effect of systemic administration of ISDN on facial and hindpaw formalin test}

In saline treated rats $(\mathrm{n}=8)$, subcutaneous injection of formalin into the right vibrissa pad causes 2-phases nociceptive rubbing response: an early, short-lasting phase 1 (0-3 min) and a late, long-lasting phase 2 (15-30 min), separated by an interphase with no rubbing (Fig. 1A). The durations of phase 1 and 2 rubbing were $35 \pm 10 \mathrm{sec}$ and $132 \pm 13 \mathrm{sec}$, respectively.

When the facial formalin test was performed $1 \mathrm{~h}$ after ISDN injection $(\mathrm{n}=6)$, no change was observed in either phase (Fig. 1). The durations of phase 1 and 2 rubbing were $38 \pm 11 \mathrm{sec}$ and $112 \pm 10 \mathrm{sec}$, respectively (Fig. 1). On the other hand, animals tested $2 \mathrm{~h}(\mathrm{n}=8$, one-way ANOVA followed by Fisher LSD post-hoc test, $P<0.01)$ or $4 \mathrm{~h}(\mathrm{n}=8$, one-way ANOVA followed by Fisher LSD post-hoc test, $P<0.05$ ) after ISDN injection showed a significant enhancement in the duration of the rubbing behavior during phase 1. Two hours after ISDN injection, the durations of phase 1 and 2 rubbing were $76 \pm 9 \mathrm{sec}$ and $131 \pm 26 \mathrm{sec}$, respectively. Four hours after ISDN injection, the durations of phase 1 and 2 rubbing were $68 \pm 12 \mathrm{sec}$ and $129 \pm 27 \mathrm{sec}$, respectively. In addition, there was very little interphase when the test was performed $2 \mathrm{~h}$ after ISDN injection, the rubbing behavior being significantly increased during 
the second block (Kruskal-Wallis ANOVA on ranks followed by Dunn's post-hoc test, $P<0.01$, Fig. 1A).

In the saline group $(n=8)$, subcutaneous injection of formalin into the hindpaw also causes a 2-phases nociceptive licking response: an early, short-lasting phase 1 (0-3 min) and a late, long-lasting phase 2 (12-30 min). The duration of phase 1 and 2 liking are presented in Fig. 2. Rats tested $2 \mathrm{~h}$ after ISDN administration showed no change in either phase of the hindpaw formalin test.

\section{Effect of systemic administration of ISDN on MDH neuronal activity}

ERK1/2 activation was used as a marker of MDH neuronal activation. To characterize the population of pERK1/2 immunopositive cells, double immunofluorescence labeling for pERK1/2 and the neuronal marker, NeuN, was performed. As shown in Fig. 3, virtually all pERK1/2 immunopositive cells were also immunoreactive for NeuN, indicating that $\mathrm{pERK} 1 / 2$ was induced in MDH neurons.

In saline treated rats, formalin injection into the vibrissa pad resulted in a strong ERK1/2 phosphorylation in the ipsilateral (Fig. 4A, C), but not contralateral, MDH. Immunostaining was localized within dendrites, soma cytoplasm and nuclei. The number of phospho-ERK1/2immunoreactive cells/section on the ipsilateral side $(6.5 \pm 1.4)$ was much larger (paired Student's $t$ test, $P<0.01)$ than that on the contralateral $(1.1 \pm 0.6)$ side. Within ipsilateral MDH, ERK1/2 phosphorylation predominated in lamina I and outer lamina II ( $\mathrm{II}_{\mathrm{o}}$ ) (one-way RM ANOVA followed by Fisher LSD post-hoc test, $\left.\mathrm{F}_{7,14}=24.441, P<0.001\right)$. None or very few phopho-ERK1/2 cells were observed in the inner lamina II (IIi) and in laminae III-V.

ISDN injection enhanced significantly the number phopho-ERK1/2-immunoreactive cells/section evoked by formalin injection only on the ipsilateral MDH. The number of phospho-ERK1/2 cells/section on ipsilateral MDH $(11.3 \pm 1.8)$ was much larger (paired 
Student's $t$ test, $P<0.001)$ than that on contralateral MDH in the same rats $(0.8 \pm 0.3)$. Within ipsilateral MDH, phopho-ERK1/2-immunoreactive cells tended to be concentrated within laminae $\mathrm{I}_{-} \mathrm{II}_{\mathrm{o}}$ (one-way RM ANOVA followed by Fisher LSD post-hoc test, $\mathrm{F}_{7,14}=39.112$, $P<0.001$, Fig. 4B, C). Finally, the number of phopho-ERK1/2-immunoreactive cells/section in the lamina $\mathrm{I}-\mathrm{II}_{\mathrm{o}}$ was significantly [two-way ANOVA followed by Duncan's post-hoc test, with treatment $\left(\mathrm{F}_{1,42}=6.169, P<0.05\right)$ and lamina $\left(\mathrm{F}_{2,42}=43.810, P<0.001\right)$ as factors $]$ larger in ISDN treated rats than in saline treated rats.

\section{Effect of systemic administration of ISDN on the C-fiber-evoked responses of the trigeminal}

\section{WDR neurons}

A total of 12 WDR neurons were recorded within the MDH. None of them exhibited spontaneous activity. All had an ipsilateral receptive field that included the maxillary and/or the ophthalmic regions. They respond to both innocuous and noxious mechanical stimuli and increased their firing rate as stimulus intensity increased into the noxious range. When percutaneous electrical stimuli were applied to the center of the cutaneous receptive field of these WDR neurons, responses due to peripheral activation of A- and C-fibers could be observed for all recorded neurons. Mean thresholds and latencies of C-fiber-evoked responses were $7.8 \pm 1.0 \mathrm{~mA}$ and $74.2 \pm 5.1 \mathrm{~ms}$, respectively. Computed conduction velocities $(\sim 0.5$ m. $\sec ^{-1}$ ) were in the range of those previously reported for C-fibers (Boyer et al., 2014; Lapirot et al., 2011).

ISDN administration did not change the level of spontaneous activity of trigeminal WDR neurons $(\mathrm{n}=12)$. But, it facilitated C-fiber-evoked responses (RM ANOVA followed by Dunnett's post-hoc test, $\mathrm{n}=6, P<0.01)$. Fig. $5 \mathrm{~A}$ illustrates the typical facilitation of C-fiberevoked response. Such facilitation of C-fiber-evoked responses was observed in 6 of 12 WDR neurons. Data from the facilitated trigeminal WDR neurons are summarized in Fig. 5B. The 
facilitation was significant at 60 min (RM ANOVA followed by Dunnett's post-hoc test, $\mathrm{n}=6$, $P<0.05)$ and reached a peak within $105 \min (45.9 \pm 10.9 \%$ of baseline, RM ANOVA followed by Dunnett's post-hoc test, $\mathrm{n}=6, P<0.01$ ), and lasted for at least $120 \mathrm{~min}$. 


\section{DISCUSSION}

The present study investigated whether the nitric oxide donor, isosorbide dinitrate (ISDN), leads to significant: i) alterations in the cephalic and extracephalic cutaneous sensitivities, and ii) changes in MDH neuronal activity. Using the facial and hindpaw formalin tests, we found that systemic administration of ISDN increases selectively the first phase and interphase of the facial formalin test, but does not change either phase of the hindpaw formalin one. Monitoring neuronal activity within MDH with phospho-ERK1/2 immunoreactivity shows that ISDN alone does not activate, but significantly increases the number of formalin-induced phospho-ERK1/2 cells on the ipsilateral, but not the contralateral, MDH. Accordingly, extracellular unit recordings show that ISDN does not activate, but potentiates the facial C-fiber-evoked responses of trigeminal WDR neurons.

\section{ISDN induced selectively cephalic but not extracephalic hyperalgesia}

Systemic NTG was previously shown to induce extracephalic heat and mechanical allodynia in mice (Bates et al., 2010; Brennan et al., 2013; Farkas et al., 2016; Pradhan, et al., 2014) and rats (Ferrari et al., 2016; Harrington et al., 2011; Tassorelli et al., 1995). The effect of systemic NTG on the hindpaw formalin test has already been investigated by only one other laboratory (Greco et al., 2015; Tassorelli et al., 1995, 2005) who reported that NTG increases selectively the second phase of the hindpaw formalin test. Using ISDN, another nitric oxide donor, we found here no change in either phase of the hindpaw formalin test. Nevertheless, our results are consistent with clinical findings reporting no extracephalic cutaneous hypersensitivity in healthy subjects (Thomsen et al., 1996) and migraineurs (de Tommaso et al., 2004) after NTG administration. 
The development of extracephalic cutaneous hypersensitivity has been attributed to sensitization of trigeminovascular thalamic nociceptive neurons (Bernstein and Burstein, 2012), activation of descending pain-facilitating processes from the rostral ventromedial medulla (Edelmayer et al., 2009), impairment of descending pain inhibitory controls (Boyer et al., 2014) and/or sensitization of the spinal dorsal horn (Boyer et al., 2014). Of note, in the two latter studies, dural nociception with inflammatory soup could produce an extracephalic cutaneous hypersensitivity only if it had a high-intensity (Edelmayer et al., 2009) or was repeated (Boyer et al., 2014). Thus, the nitric oxide-donor concentration, we used here, might not be sufficient to impair the descending pain modulatory controls and/or sensitize the spinal dorsal horn. In line with this hypothesis, low doses of NTG $(0.5$ or $1 \mathrm{mg} / \mathrm{kg})$ fail to induce extracephalic cutaneous hypersensitivity (Bates et al., 2010, Brennan et al., 2013; but see Ferrari et al., 2016).

The discrepancies between our and other results (Greco et al., 2015; Tassorelli et al., 1995; 2005) in the hindpaw formalin test, could also be attributed to methodological differences. On the one hand, we used the duration of licking behavior as pain index, while the other laboratory (Greco et al., 2015; Tassorelli et al., 1995) used the flinching behavior. Previous findings suggest that the generation of licking and flinching behaviors result from the activation of different neural pathways. Indeed, mid-thoracic spinal transection has no effect on formalininduced flinching (Coderre et al., 1994), but completely inhibits formalin-induced licking (Wheeler-Aceto and Cowan, 1991). Different effects on flinching and licking have also been observed with various pharmacological drugs, e.g. systemic naloxone (Wheeler-Aceto and Cowan, 1993), amitriptyline (Sawynok and Reid, 2001), phenobarbital (Abbott et al., 1995) (increase and decrease, respectively), as well as spinal neurotoxins 5,6-dihydroxytryptamine and 6-hydroxydopamine (Tjølsen et al., 1991) (no effect and decrease, respectively). Similarly, rats exposed during early life to liposaccharide displayed enhanced formalin-induced flinching but not licking at the adult age (Zouikr et al., 2014). On the other hand, the observed effects 
with NTG might be non-specific, caused by substances used to dissolve NTG. Indeed, NTG usually must be dissolved in a mixture of alcohol and propylene glycol. Because very large amounts of NTG are necessary, the amount of injected alcohol and propylene glycol are considerable (Olesen and Jansen-Olesen, 2012).

Our results show that the administration of ISDN is nevertheless able to induce cephalic hyperalgesia. We found that systemic administration of ISDN selectively increases the first phase and interphase, but not the second phase, of the facial formalin test. This effect was significant $2 \mathrm{~h}$ after ISDN injection and lasted for at least $4 \mathrm{~h}$. The development of ISDNinduced cephalic hyperalgesia resembles that of delayed migraine headache (Ashina et al., 2007). The present findings are in agreement with previous studies showing that NTG facilitates CGRP-induced face rubbing behavior (Capuano et al., 2014; Yao and Sessle, 2008). However, they are not consistent with previous findings that noted either no change on both phases (Grigoraay et al., 2013) or an increase in the duration of the rubbing behavior during only the second phase of the facial formalin test (Greco et al., 2015) after systemic NTG (10 mg/kg). These conflicting data may in part be explained by differences in species [mice (Grigoraay et al., 2013) vs. rat (Greco et al., 2015)], nitric oxide donors [ISDN (present study) vs. NTG (Greco et al., 2015)] or measured pain behavior: we measured the duration of the face rubbing responses with the forepaw and not with the hindpaw, while Greco et al. (2015) measured the duration of both the rubbing and scratching behavior evoked by the forepaw and hindpaw, respectively.

The first phase of the formalin response is generally attributed to chemical activation of nociceptors, whereas the second phase is due to the release of local endogenous mediators responsible for the sensitization of nociceptors and central nociceptive neurons (Raboisson and Dallel, 2004). The preferential effect of ISDN on the first phase of the facial formalin test suggests that the most important mechanism underlying ISDN-induced cephalic hyperalgesia 
is increasing available nitric oxide at peripheral sites and/or central terminals of meningeal nociceptors within $\mathrm{MDH}$.

Our observation that systemic administration of nitric oxide donor induces hyperalgesia in the maxillary division is consistent with clinical studies indicating that patients develop cephalic hypersensitivity, not only in the ophthalmic area, but also in maxillary regions during migraine attack (Ashkenazi et al., 2007; Cooke et al., 2007; Guy et al., 2010; Kitaj and Klink, 2005; Yoon et al., 2009). Similarly, preclinical studies have described both dura-sensitive neurons with mandibular and maxillary receptive fields and dura-sensitive neurons that can expand their cutaneous receptive fields to these areas after chemical stimulation of the meninges (Boyer et al., 2014; Burstein et al., 2000; Yamamura et al., 1999). The presence of such neurons may explain the hypersensitivity of the in maxillary region during meningeal stimulation in awake patients (Wirth and Van Buren, 1971; Yamamura et al., 1999) as well as during headache attacks.

\section{ISDN does not active, but sensitize MDH neurons}

ERK1/2 activation was used here as an anatomical marker of MDH neuronal activation (Gao and Ji, 2009). ERK1/2 activation also contributes to pain hypersensitivity (Gao and Ji, 2009). In the medullary and spinal dorsal horns, it is activated by mechanical, thermal and chemical noxious, but not innocuous, stimuli (Ji et al., 1999; Miraucourt et al., 2009). We found no or very few phospho-ERK1/2-immunoreactive cells in the MDH of saline- and ISDN-pretreated rats, contralateral to the formalin injection side. Similarly, results from our electrophysiological study revealed that no trigeminal WDR neuron started to fire spontaneously after ISDN administration. In addition, neither NTG (Capuano et al., 2014; Yao and Sessle, 2008) nor ISDN (present study), alone, caused any significant change in the face rubbing behavior. This suggests that ISDN per se does not activate MDH neurons. Of note, however, 
immunohistochemical and electrophysiological studies have obtained conflicting results on NTG-induced activation of MDH neurons. While some authors (Jones et al., 2001; Martin and Martin, 2001; Offenhauser et al., 2005; Tassorelli et al., 2005) failed to detect any NTG-induced Fos expression, others observed Fos expression in rats (Knyihar-Csillik et al., 2008; Pardutz et al., 2000; Tassorelli et al., 1995) as well as mice (Bates et al., 2010; Brennan et al., 2013) after a single NTG injection. Interestingly, studies in which Fos expression was detected, used rather high doses (10 mg/kg) of NTG (Bates et al., 2010; Brennan et al., 2013; Knyihar-Csillik et al., 2008; Pardutz et al., 2000; Tassorelli et al., 1995, but see Ramachandran et al., 2012) whereas those where Fos expression was not detected used low doses $(<5 \mathrm{mg} / \mathrm{kg})$ of NTG (Jones et al., 2001; Martin and Martin, 2001; Offenhauser et al., 2005; Tassorelli et al., 2005). Similarly, electrophysiological studies reported either no change (Jones et al., 2001) or an increase in the ongoing activity of trigeminal WDR neurons (Feistel al., 2013; Koulchitsky et al., 2004; Lambert et al., 2000) following systemic administration of NTG. Therefore, as already suggested above, it is possible that we used here a low dose of ISDN, that is, sufficient to sensitize, but not to activate, MDH nociceptive neurons. The different chemical structures of the two drugs might also contribute to this difference between NTG- and ISDN-induced neuronal activation. Indeed, ISDN has a longer onset and duration of action than NTG (Willis et al., 1976). Moreover, the hypotensive effect of ISDN is 2000 times smaller than that of NTG (Manabe et al., 2001). Finally, the present and previous studies used different anatomical markers of neuronal activation. While almost all previous studies used Fos protein as an anatomical marker of neuronal activation (see above), we used phospho-ERK1/2. Although, both Fos protein and ERK1/2 phosphorylation are good markers for nociception-induced neuronal activation within the spinal dorsal horn and $\mathrm{MDH}$, they differ in many ways (Gao and Ji, 2009): compared with Fos protein, ERK1/2 phosphorylation is more dynamic with a quicker induction, different cellular and subcellular localizations and a closer correlation to pain 
behavior. Thus, phospho-ERK1/2 appears to be a better marker than Fos protein for central sensitization (Gao and Ji, 2009).

The other main finding of the present study is that ERK1/2 activation in MDH, ipsilateral to the formalin injection site was clearly potentiated by ISDN. Phospho-ERK1/2-immunoreacive cells were confined almost exclusively within the most superficial laminae (I and outer lamina II) of the MDH that contain predominantly nociceptive specific neurons (Sessle, 2000). Similarly, Fos response to infraorbital injection of capsaicin can be potentiated by NTG (Jones et al., 2001). Accordingly, our in vivo electrophysiological results show that ISDN facilitates C-fiberevoked responses in 50\% of trigeminal WDR neurons. Infusion of NTG (Jones et al., 2001) or sodium nitroprusside (Koulchitsky et al., 2004) also potentiates the responses to electrical stimulation of the face, but the effects of nitric oxide donors varies between neurons suggesting that only a fraction of MDH neurons is readily under the control of nitric oxide (Feistel al., 2013). The present results are also consistent with a previous report showing NTG infusion results in a delayed increase in the mechano-sensitivity, with no significant change in the ongoing discharges, of primary afferent meningeal nociceptors (Zhang et al., 2013). Consistently, upon NTG, the decrease in periorbital von Frey thresholds following repeated dural inflammation appears to be potentiated (Oshinsky and Gomonchareonsiri, 2007) and that in spontaneous allodynia rats to be extended, from 1.5 to $5 \mathrm{~h}$ (Oshinsky et al., 2012). Altogether, these data suggest that nitric oxide does not activate $\mathrm{MDH}$ neurons directly but rather facilitates their response to peripheral nociceptive inputs. Thus our results support the statement that nitric oxide-related increased activity of the MDH is mediated by central facilitation of trigeminal neuronal response to afferent traffic that originate from peripheral nociceptors (Zhang et al., 2013) or to increased presynaptic activity on central terminal of meningeal nociceptors (Oshinsky and Gomonchareonsiri, 2007). Thus, NO, alone, does not appear to be sufficient to cause migraine pain. Nevertheless, migraine patients may have an additional level of susceptibility such that a basal neuronal response can lead to headache.

In summary, the present study characterizes for the first time the behavioral and neuronal effects of the administration of the nitric oxide donor, ISDN. We found that ISDN induces cutaneous hypersensitivity at cephalic but not extra-cephalic level that is associated with sensitization but not activation of $\mathrm{MDH}$ neurons. This model better mimics the clinical 
condition and offers another possibility to study the role of nitric oxide donor in the physiopathology of headache. 


\section{Conflict of interest}

None of the authors have any conflict of interest to declare

\section{Acknowledgments}

This work was supported by funding from Institut National de la Santé et de la Recherche Médicale (INSERM), Université Clermont1 (France), and Région Auvergne (France). We thank Pr A Artola for helpful comments on this manuscript and A-M Gaydier for secretarial assistance.

\section{Highlights}

- Isosorbide dinitrate induces a cephalic but not extracephalic hyperalgesia.

- Isosorbide dinitrate does not activate, but sensitize medullary dorsal horn neurons.

- This animal model better mimics the clinical features of migraine.

\section{Author's contribution}

All authors had full access to all the data in the study and take responsibility for the integrity of the data and the accuracy of the data analysis. Study concept and design: PL and RD. Acquisition of data: JMFR, LD, AD, PL, JLM. Analysis and interpretation of data: JMFR, LD, AD, PL, JLM and RD. Drafting of the manuscript: RD. All authors have approved the final version of the manuscript. 


\section{REFERENCES}

Abbott FV, Franklin KB, Westbrook RF (1995) The formalin test: scoring properties of the first and second phases of the pain response in rats. Pain 60:91-102.

Alvarez P, Dieb W, Hafidi A, Voisin DL, Dallel R (2009) Insular cortex representation of dynamic mechanical allodynia in trigeminal neuropathic rats. Neurobiol Dis 33:89-95.

Ashina M, Hansen JM, Olesen J (2013) Pearls and pitfalls in human pharmacological models of migraine: 30 years' experience. Cephalalgia 33:540-53.

Ashkenazi A, Sholtzow M, Shaw JW, Burstein R, Young WB (2007) Identifying cutaneous allodynia in chronic migraine using a practical clinical method. Cephalalgia 27:111-7.

Bates EA, Nikai T, Brennan KC, Fu YH, Charles AC, Basbaum AI, Ptácek LJ, Ahn AH (2010) Sumatriptan alleviates nitroglycerin-induced mechanical and thermal allodynia in mice. Cephalalgia 30:170-8.

Bellantonio P, Micieli G, Buzzi MG, Marcheselli S, Castellano AE, Rossi F, Nappi G (1997) Haemodynamic correlates of early and delayed responses to sublingual administration of isosorbide dinitrate in migraine patients: a transcranial Doppler study. Cephalalgia 17:1837.

Bernstein C, Burstein R (2012) Sensitization of the trigeminovascular pathway: perspective and implications to migraine pathophysiology. J Clin Neurol 8:89-9.

Bigal ME, Ashina S, Burstein R, Reed ML, Buse D, Serrano D, Serrano D, Lipton RB; AMPP Group (2008) Prevalence and characteristics of allodynia in headache sufferers: a population study. Neurology 70:1525-33.

Boyer N, Dallel R, Artola A, Monconduit L (2014) General trigeminospinal central sensitization and impaired descending pain inhibitory controls contribute to migraine progression. Pain 155:1196-205. 
Brennan KC, Bates EA, Shapiro RE, Zyuzin J, Hallows WC, Huang Y, Lee HY, Jones CR, Fu

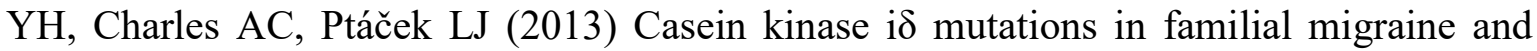
advanced sleep phase. Sci Transl Med 5:183ra56, 1-11.

Burstein R, Yarnitsky D, Goor-Aryeh I, Ransil BJ, Bajwa ZH (2000) An association between migraine and cutaneous allodynia. Ann Neurol 47:614-24.

Capuano A, Greco MC, Navarra P, Tringali G (2014) Correlation between algogenic effects of calcitonin-gene-related peptide (CGRP) and activation of trigeminal vascular system, in an in vivo experimental model of nitroglycerin-induced sensitization. Eur J Pharmacol 740:97102.

Castellano AE, Micieli G, Bellantonio P, Buzzi MG, Marcheselli S, Pompeo F, Rossi F, Nappi G (1998) Indomethacin increases the effect of isosorbide dinitrate on cerebral hemodynamic in migraine patients: pathogenetic and therapeutic implications. Cephalalgia 18:622-30.

Coderre TJ, Yashpal K, Henry JL (1994) Specific contribution of lumbar spinal mechanisms to persistent nociceptive responses in the formalin test. Neuroreport 5:1337-40.

Cooke L, Eliasziw M, Becker WJ (2007) Cutaneous allodynia in transformed migraine patients. Headache 47:531-9.

de Tommaso M1, Libro G, Guido M, Difruscolo O, Losito L, Sardaro M, Cerbo R (2004) Nitroglycerin induces migraine headache and central sensitization phenomena in patients with migraine without aura: a study of laser evoked potentials. Neurosci Lett 363:272-5.

Edelmayer RM, Vanderah TW, Majuta L, Zhang ET, Fioravanti B, De Felice M, Chichorro JG, Ossipov MH, King T, Lai J, Kori SH, Nelsen AC, Cannon KE, Heinricher MM, Porreca F (2009) Medullary pain facilitating neurons mediate allodynia in headache-related pain. Ann Neurol 65:184-93. 
Farkas S, Bölcskei K, Markovics A, Varga A, Kis-Varga Á, Kormos V, Gaszner B, Horváth C, Tuka B, Tajti J, Helyes Z (2016) Utility of different outcome measures for the nitroglycerin model of migraine in mice. J Pharmacol Toxicol Methods 77:33-44.

Feistel S, Albrecht S and Messlinger K (2013) The calcitonin gene-related peptide receptor antagonist MK-8825 decreases spinal trigeminal activity during nitroglycerin infusion. $\mathrm{J}$ Headache Pain 20:14:93.

Ferrari LF, Levine JD, Green PG (2016) Mechanisms mediating nitroglycerin-induced delayedonset hyperalgesia in the rat. Neuroscience 317:121-9.

Gao YJ, Ji RR (2009) c-Fos and pERK, which is a better marker for neuronal activation and central sensitization after noxious stimulation and tissue injury? Open Pain J 2:11-17.

Greco R, Bandiera T, Mangione AS, Demartini C, Siani F, Nappi G, Sandrini G, Guijarro A, Armirotti A, Piomelli D, Tassorelli C (2015) Effects of peripheral FAAH blockade on NTGinduced hyperalgesia--evaluation of URB937 in an animal model of migraine. Cephalalgia $35: 1065-76$.

Grigoraay VA, Luca A, DondaÅŸ A, Alexa T, Mungiu OC, Bohotin CR (2013) Glyceryl trinitrate has opposite effects on different experimental models of pain. J Headache Pain. 14(Suppl 1): P90.

Guy N, Marques AR, Orliaguet T, Lanteri-Minet M, Dallel R, Clavelou P (2010) Are there differences between cephalic and extracephalic cutaneous allodynia in migraine patients? Cephalalgia 30:881-6.

Harrington MG, Chekmenev EY, Schepkin V, Fonteh AN, Arakaki X (2011) Sodium MRI in a rat migraine model and a NEURON simulation study support a role for sodium in migraine. Cephalalgia 31:1254-65.

Ji RR, Baba H, Brenner GJ, Woolf CJ (1999) Nociceptive-specific activation of ERK in spinal neurons contributes to pain hypersensitivity. Nat Neurosci 2:1114-9. 
Jones MG, Lever I, Bingham S, Read S, McMahon SB, Parsons A (2001) Nitric oxide potentiates response of trigeminal neurones to dural or facial stimulation in the rat. Cephalalgia 21:643-55.

Kaufmann D, Bates EA, Yagen B, Bialer M, Saunders GH, Wilcox K, White HS, Brennan KC. sec-Butylpropylacetamide (SPD) has antimigraine properties. Cephalalgia (in press) 2015, Nov 13. pii: 0333102415612773.

Kitaj MB, Klink M (2005) Pain thresholds in daily transformed migraine versus episodic migraine headache patients. Headache 45:992-8.

Knyihar-Csillik E, Mihaly A, Krisztin-Peva B, Robotka H, Szatmari I, Fulop F, Toldi J, Csillik B, Vecsei L (2008) The kynurenate analog SZR-72 prevents the nitroglycerol-induced increase of c-fos immunoreactivity in the rat caudal trigeminal nucleus: comparative studies of the effects of SZR-72 and kynurenic acid. Neurosci Res 61:429-32.

Koulchitsky S, Fischer MJ, De Col R, Schlechtweg PM, Messlinger K (2004) Biphasic response to nitric oxide of spinal trigeminal neurons with meningeal input in rat--possible implications for the pathophysiology of headaches. J Neurophysiol 92:1320-8.

Lambert GA, Donaldson C, Boers PM, Zagami AS (2000) Activation of trigeminovascular neurons by glyceryl trinitrate. Brain Res 887:203-10.

Lapirot O, Melin C, Modolo A, Nicolas C, Messaoudi Y, Monconduit L, Artola A, Luccarini P, Dallel R (2011) Tonic and phasic descending dopaminergic controls of nociceptive transmission in the medullary dorsal horn. Pain 152:1821-31.

Manabe T, Yamamoto A, Satoh K, Ichihara K (2011) Tolerance to nitroglycerin induced by isosorbide-5-mononitrate infusion in vivo. Biol Pharm Bull 24:1370-2.

Manack A, Buse DC, Serrano D, Turkel CC, Lipton RB (2011) Rates, predictors, and consequences of remission from chronic migraine to episodic migraine. Neurology 76:71118. 
Martin RS, Martin GR (2001) Investigations into migraine pathogenesis: time course for effects of m-CPP, BW723C86 or glyceryl trinitrate on appearance of Fos-like immunoreactivity in rat trigeminal nucleus caudalis (TNC). Cephalalgia 21:46-52.

Miraucourt LS, Moisset X, Dallel R, Voisin DL (2009) Glycine inhibitory dysfunction induces a selectively dynamic, morphine-resistant, and neurokinin 1 receptorindependent mechanical allodynia. J Neurosci 29:2519-27.

Offenhauser N, Zinck T, Hoffmann J, Schiemann K, Schuh-Hofer S, Rohde W, Arnold G, Dirnagl U, Jansen-Olesen I, Reuter U (2005) CGRP release and c-fos expression within trigeminal nucleus caudalis of the rat following glyceryltrinitrate infusion. Cephalalgia $25: 225-36$

Olesen J, Jansen-Olesen I (2012) Towards a reliable animal model of migraine. Cephalalgia $32: 578-80$.

Oshinsky ML, Gomonchareonsiri S (2007) Episodic dural stimulation in awake rats: a model for recurrent headache. Headache 47:1026-36.

Oshinsky ML, Sanghvi MM, Maxwell CR, Gonzalez D, Spangenberg RJ, Cooper M, Silberstein SD (2012) Spontaneous trigeminal allodynia in rats: a model of primary headache. Headache 52:1336-49.

Pardutz A, Krizbai I, Multon S, Vecsei L, Schoenen J (2000) Systemic nitroglycerin increases nNOS levels in rat trigeminal nucleus caudalis. Neuroreport 11:3071-5.

Paxinos G. Watson C (2007) The rat brain in stereotaxic coordinates. New York: Academic Press.

Peirs C, Bourgois N, Artola A, Dallel R (2016) Protein Kinase C $\gamma$ Interneurons Mediate Cfiber-induced Orofacial Secondary Static Mechanical Allodynia, but Not C-fiber-induced Nociceptive Behavior. Anesthesiology 124:1136-52. 
Pradhan AA, Smith ML, McGuire B, Tarash I, Evans CJ, Charles A (2014) Characterization of a novel model of chronic migraine. Pain 155:269-74.

Raboisson P. Dallel R (2004) The orofacial formalin test. Neurosci Biobehav Rev 28:219-26.

Ramachandran R, Bhatt DK, Ploug KB, Olesen J, Jansen-Olesen I, Hay-Schmidt A, Gupta S (2012) A naturalistic glyceryl trinitrate infusion migraine model in the rat. Cephalalgia $32: 73-84$.

Sawynok J, Reid A (2001) Antinociception by tricyclic antidepressants in the rat formalin test: differential effects on different behaviours following systemic and spinal administration. Pain 93:51-9.

Sessle BJ (2000) Acute and chronic craniofacial pain: brainstem mechanisms of nociceptive transmission and neuroplasticity, and their clinical correlates. Crit Rev Oral Biol Med 11:5791.

Stovner LJ, Andree C (2010) Prevalence of headache in Europe: a review for the Eurolight project. J Headache Pain 11:289-99.

Tassorelli C, Cappelletti D, Sandrini G, Nappi G (2005) Comparative analysis of the neuronal activation and cardiovascular effects of nitroglycerin, sodium nitroprusside and L-arginine. Brain Res 1051:17-24

Tassorelli C, Greco R, Wang D, Sandrini M, Sandrini G, Nappi G (2003) Nitroglycerin induces hyperalgesia in rats-a time-course study. Eur J Pharmacol 464:159-62.

Tassorelli C, Joseph SA (1995) Systemic nitroglycerin induces Fos immunoreactivity in brainstem and forebrain structures of the rat. Brain Res 682:167-81.

Thomsen LL, Brennum J, Iversen HK, Olesen J (1996) Effect of a nitric oxide donor (glyceryl trinitrate) on nociceptive thresholds in man. Cephalalgia 16:169-74. 
Tjølsen A, Berge OG, Hole K (1991) Lesions of bulbo-spinal serotonergic or noradrenergic pathways reduce nociception as measured by the formalin test. Acta Physiol Scand 142:22936.

Wheeler-Aceto H, Cowan A (1993) Naloxone causes apparent antinociception and pronociception simultaneously in the rat paw formalin test. Eur J Pharmacol 236:193-9.

Wheeler-Aceto H, Cowan A (1991) Standardization of the rat paw formalin test for the evaluation of analgesics. Psychopharmacology (Berl) 104:35-44.

Willis WH Jr, Russell RO Jr, Mantle JA, Ratshin RA, Rackley CE (1976) Hemodynamic effects of isosorbide dinitrate vs nitroglycerin in patients with unstable angina. Chest 69:15-22.

Wirth FP Jr, Van Buren JM. Referral of pain from dural stimulation in man. J Neurosurg $34: 630-42,1971$.

Yamamura H, Malick A, Chamberlin NL, Burstein R (1999) Cardiovascular and neuronal responses to head stimulation reflect central sensitization and cutaneous allodynia in a rat model of migraine. J Neurophysiol 81:479-93.

Yao D, Sessle BJ (2008) Nitroglycerin facilitates calcitonin gene-related peptide-induced behavior. Neuroreport 19:1307-11.

Yoon MS, Mueller D, Hansen N, Poitz F, Slomke M, Dommes P, Diener HC, Katsarava Z, Obermann M (2010) Prevalence of facial pain in migraine: a population-based study. Cephalalgia. 30:92-6.

Zhang X, Kainz V, Zhao J, Strassman AM, Levy D (2013) Vascular extracellular signalregulated kinase mediates migraine-related sensitization of meningeal nociceptors. Ann Neurol 73:741-50.

Zimmermann M (1983) Ethical guidelines for investigations of experimental pain in conscious animals. Pain 16:109-10. 
Zouikr I, James MH, Campbell EJ, Clifton VL, Beagley KW, Dayas CV, Hodgson DM (2014) Altered formalin-induced pain and Fos induction in the periaqueductal grey of preadolescent rats following neonatal LPS exposure. PLoS One 9(5):e98382. 


\section{Figure legends}

Fig. 1. Effect of the systemic administration of isosorbide dinitrate (ISDN) on the facial formalin test. A. Time courses of the facial rubbing response to subcutaneous injection of formalin $(50 \mu 1,1 \%)$ into the vibrissa pad in rats previously intraperitoneally injected with saline or ISDN. ISDN $(10 \mathrm{mg} / \mathrm{kg})$ was injected $1(\mathrm{n}=6), 2(\mathrm{n}=8)$, and $4 \mathrm{~h}(\mathrm{n}=8)$, and saline $2 \mathrm{~h}(\mathrm{n}=8)$ before formalin. The recording time was divided into 15 blocks of 3 min, and a nociceptive score was determined for each block by measuring the number of seconds that the animals spent rubbing the injected area with the ipsilateral foredpaw. The first phase of rubbing activity was measured during the first block (i.e., 0 - $3 \mathrm{~min}$ ) and the second phase was identified between blocks 4 and 10 (i.e., 15 - $30 \mathrm{~min}$ ) after the formalin injection. B. Bar histograms of the duration of the phases 1 and 2 of the rubbing behavior in the four groups of rats. Statistical analysis was performed using one-way ANOVA followed by Fisher post-hoc LSD test (normally distributed data, $\mathrm{F}_{3,26}=3.917, P<0.05$ ). ${ }^{*} P<0.05$; $* * P<0.01$.

Fig. 2. Effect of the systemic administration of isosorbide dinitrate (ISDN) on the hindpaw formalin test. A. Time courses of the hindpaw licking responses to subcutaneous injection of formalin $(50 \mu 1,1 \%)$ into the plantar hindpaw in rats previously intraperitoneally injected with saline $(\mathrm{n}=8)$ or ISDN $(\mathrm{n}=8,10 \mathrm{mg} / \mathrm{kg}) 2 \mathrm{~h}$ before formalin. B. Bar histograms of the duration of licking behavior during the phases 1 and 2 of the hindpaw formalin test.

Fig. 3. Fluorescence images of pERK-1/2 immunopositive cells (red) and NeuN positive neurons (green) in the MDH. The merged image on the right shows that virtually all pERK1/2 cells were immunoreactive for NeuN, indicating that pERK1/2 expression was restricted to neurons. Bar is $50 \mu \mathrm{m}$. 
Fig. 4. Distribution of phospho-ERK-1/2-immunoreactive cells within the medullary dorsal horn (MDH). A. Examples of phospho-ERK1/2 immunolabeling in the MDH of control (saline) and ISDN injected rats. ISDN (10 mg/kg) or saline were intraperitoneally injected $2 \mathrm{~h}$ before subcutaneous injection of formalin $(50 \mu 1,1 \%)$ into the right vibrissa pad. Subcutaneous formalin triggers ERK1/2 phosphorylation within almost exclusively laminae I-IIo of the ipsilateral MDH. No phospho-ERK1/2-immunoreactive cell is observed in the contralateral MDH. B. Examples showing the enhanced phospho-ERK1/2 immunolabeling in laminae I-IIo of the ipsilateral MDH following subcutaneous injection of formalin $(50 \mu 1,1 \%)$ into the right vibrissa pad after an intraperitoneal injection of ISDN (10 mg/kg). Again no phospho-ERK1/2immunoreactive cell is observed within the contralateral MDH. C. Boxplots showing the number of phospho-ERK1/2-immunoreactive cells/section in the different laminae of the ipsilateral and contralateral MDH following subcutaneous injection of formalin $(50 \mu 1,1 \%)$ into the right vibrissa pad, $2 \mathrm{~h}$ after an intraperitoneal injection of ISDN (10 mg/ $\mathrm{kg})$ or saline ( $\mathrm{n}=8$ /group). I-IIo: laminae I and outer II; IIi: inner laminae II; III-V: laminae III-V. The data are presented as median (thick line), first and third quartiles (boxes) and minimum-maximum (whiskers). Comparisons between the two groups were performed using two-way ANOVA followed by Duncan's post-hoc test, with treatment and lamina as factors. Bar is $100 \mu \mathrm{m} * * * P$ $<0.001$.

Fig. 5. Effect of the systemic administration of isosorbide dinitrate (ISDN) on C-evoked responses of trigeminal WDR neurons. A. Histograms of C-fiber-evoked responses in one trigeminal WDR neuron to the 30 successive percutaneous electrical stimulations $(1.5 \mathrm{x}$ C-fiber threshold intensity, $0.66 \mathrm{~Hz}$ ) recorded before (left) and $105 \mathrm{~min}$ (right) after intravenous injection of ISDN (10 mg/kg). B. Summary bar histograms (mean \pm standard error of the mean) of C-fiber-evoked responses before and 15, 30, 45, 60, 75, 90, 105 and 120 min following 
infusion of ISDN. C-fiber-evoked responses are normalized to those before ISDN administration. Note that ISDN administration potentiates C-fiber-evoked responses. Comparisons were performed using RM ANOVA followed by Dunnett's post-hoc test $\left(\mathrm{F}_{5,35}=3.453, P<0.01\right) . * P<0.05, * * P<0.01$. C. Microphotograph showing the histologically confirmed (arrow) recording locus of one trigeminal WDR neuron within the MDH. 


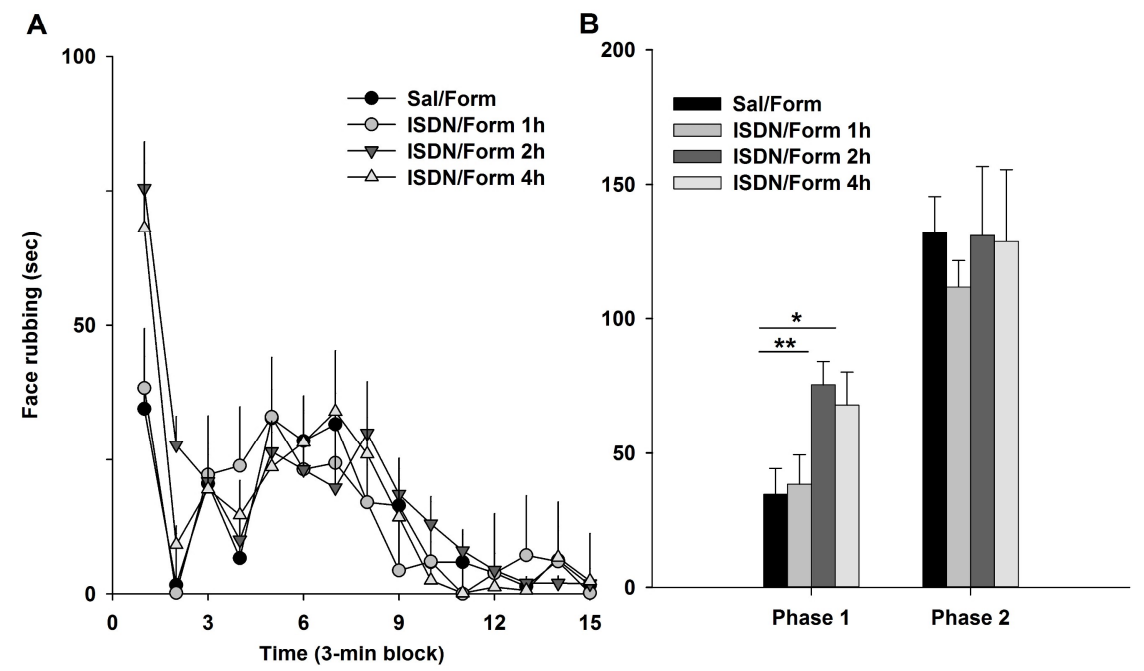




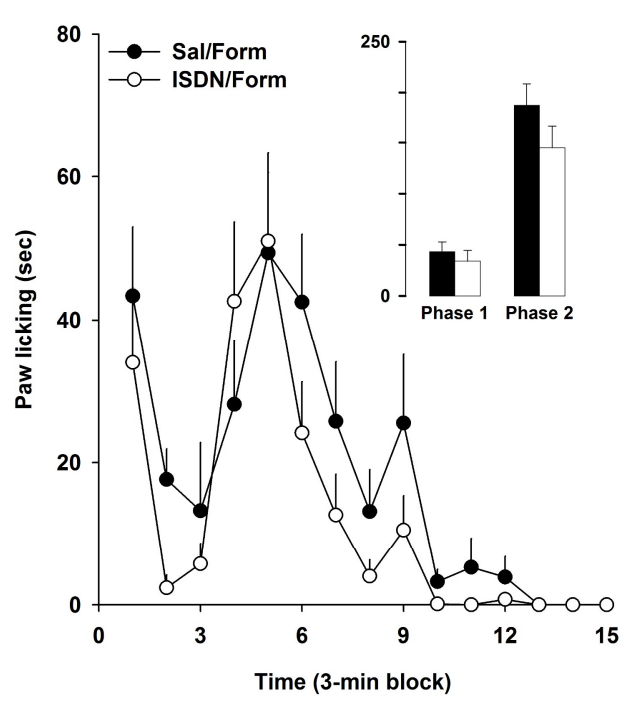




\section{NeuN}

PERK

c merged

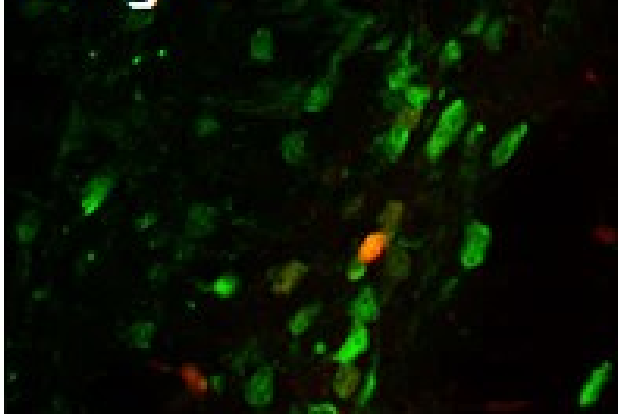


Contralateral
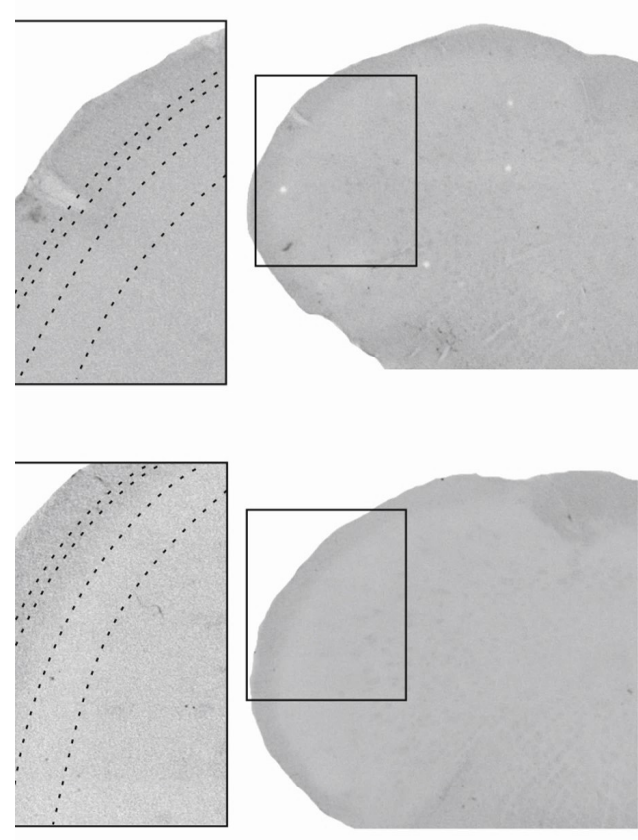

Ipsilateral
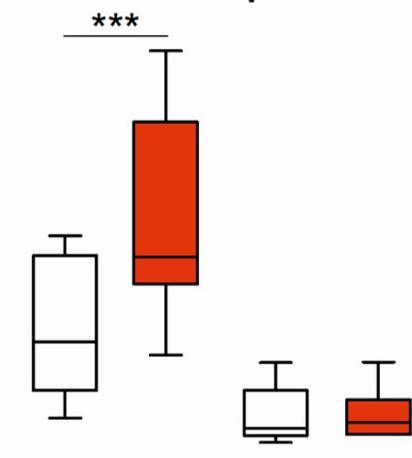

Ipsilateral
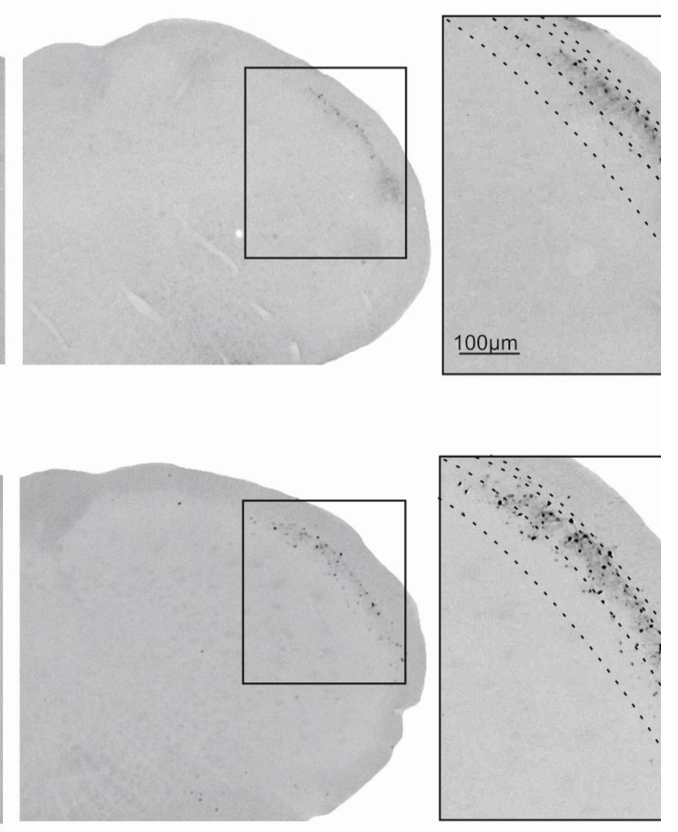

Contralateral

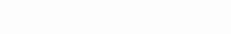

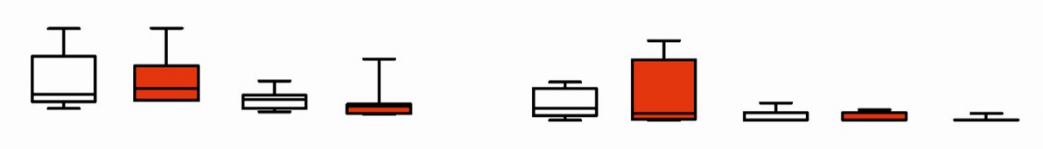
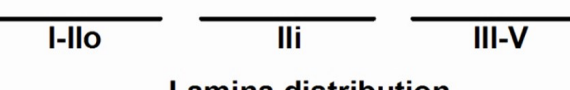

Lamina distribution

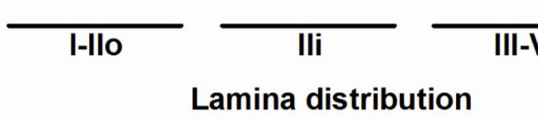




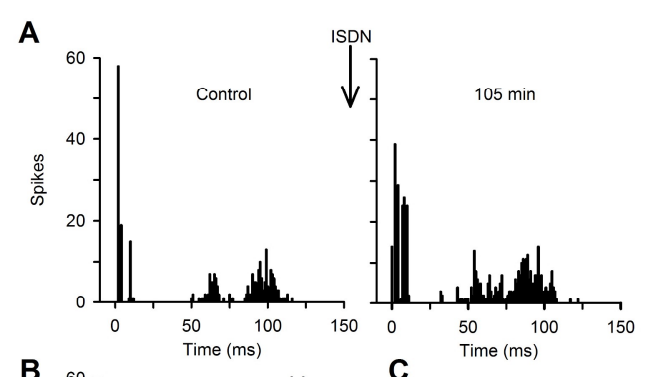

uㅔㄴㅔ 